\title{
High-frequency oscillation ventilation for hypercapnic failure of conventional ventilation in pulmonary acute respiratory distress syndrome
}

\author{
Sigrun Friesecke ${ }^{* \dagger}$, Stephanie-Susanne Stecher ${ }^{\dagger}$ and Peter Abel
}

\begin{abstract}
Introduction: High-frequency oscillation ventilation (HFOV) is regarded as particularly lung protective. Recently, HFOV has been shown to be not beneficial for acute respiratory distress syndrome (ARDS) patients in general. Due to its special physical effects, it could be beneficial, however, in inhomogeneous ARDS. This study evaluates the effect of HFOV on $\mathrm{PaCO}_{2}$ removal in hypercapnic patients with ARDS of pulmonary origin.

Methods: Between October 2010 and June 2014 patients with ARDS of pulmonary origin with $\mathrm{PaO}_{2} / \mathrm{FiO}_{2}$ ratio $>60 \mathrm{mmHg}$, but respiratory acidosis ( $\mathrm{pH}<7.26)$ under optimized protective ventilation were switched to HFOV, using moderate airway pressure (adopting the mean airway pressure of the prior ventilation). Data from these patients were analyzed retrospectively; $\mathrm{PaCO}_{2}$ and $\mathrm{pH}$ before, $1 \mathrm{~h}$ and $24 \mathrm{~h}$ after the start of HFOV were compared.

Results: Twenty-six patients with $\mathrm{PaO}_{2} / \mathrm{FiO}_{2}$ ratio $139 \pm 49$ and respiratory acidosis $\left(\mathrm{PaCO}_{2} 68 \pm 12 \mathrm{mmHg}\right)$ were put on HFOV after $17 \pm 22 \mathrm{~h}$ of conventional ventilation. Mean airway pressure was $19 \mathrm{~cm} \mathrm{H}_{2} \mathrm{O}$ (15 to 28). $\mathrm{PaCO}_{2}$ decreased significantly: after 1 hour the mean difference was $-14 \pm 10 \mathrm{mmHg} ; P<0.01$ and after 24 hours $-17 \pm 12 \mathrm{mmHg} ; P<0.01$; $\mathrm{n}=24 . \mathrm{CO}_{2}$ clearance improved in all but two patients; in those, extracorporeal lung support was initiated. Oxygenation remained unchanged after $1 \mathrm{~h}$ and slightly increased after $24 \mathrm{~h}$. No complications related to HFOV were observed. Twenty-two patients improved and could be weaned from HFOV. Twenty patients (77\%) were alive on day 30.

Conclusions: HFOV could be a useful alternative in patients with ARDS of pulmonary origin with hypercapnic failure of lung-protective conventional ventilation.
\end{abstract}

\section{Introduction}

High-frequency oscillation ventilation (HFOV) has been considered to be particularly lung-protective because compared with conventional ventilation - its physical characteristics may allow better avoidance of both overinflation and recurring alveolar derecruitment [1,2]. Technically, oscillations of 3 to $15 \mathrm{~Hz}$ are superimposed onto a constant airway pressure applied via a customary cuffed tracheal tube. The resulting tidal volumes (Vts) often remain below the airway dead space. Effective alveolar ventilation can be achieved nonetheless by physical mechanisms that are explained elsewhere [3-5].

\footnotetext{
* Correspondence: sigrun.friesecke@uni-greifswald.de

${ }^{\dagger}$ Equal contributors

Department of Internal Medicine B, Division of Cardiology, Pneumology and

Critical Care Medicine, University Medicine Greifswald, Ferdinand-SauerbruchStraße, 17475 Greifswald, Germany
}

Two recent multicenter studies could not show a survival benefit in adult acute respiratory distress syndrome (ARDS) patients with unselected etiologies of ARDS [6,7]. Therefore, HFOV has so far no place in routine care for ARDS. In special circumstances however, HFOV may be beneficial, mostly as a rescue therapy in oxygenation failure [2,8-10]. A substantial improvement in oxygenation $[7,11]$ and the safety of HFOV have been shown $[12,13]$ even though barotrauma is reported in a substantial number of patients $[9,14]$.

ARDS of pulmonary origin (ARDSpulm) is defined as ARDS caused by an insult primarily affecting the lungs [15]. Compared to ARDS of extrapulmonary origin, in which a hematogeneous insult leads to a diffuse damage with uniform distribution, ARDSpulm shows a distinct computed tomography (CT) morphology with a multifocal and asymmetric involvement [16]. Such inhomogeneously damaged lungs with very different local compliances are 
exposed to increased stress and strain with conventional ventilation [17]. Complete recruitment often is not possible using conventional ventilation without risk of ventilatorinduced lung injury [18]. With conventional ventilation, normally compliant alveoli are exposed to a significant risk of volutrauma due to preferential airflow into these segments [3]. As HFOV is more homogeneous and less dependent on different regional compliances [19], it should be especially advantageous in cases of inhomogeneous pulmonary damage.

We hypothesize a benefit in patients with ARDSpulm and hypercapnic failure of lung-protective conventional ventilation. Ventilatory failure has been suggested as an indication for HFOV [20] but data supporting this alternative are scarce. The main goal is to evaluate $\mathrm{CO}_{2}$ removal with HFOV in patients with ARDS with acceptable oxygenation but hypercapnic failure of conventional ventilation. We hypothesize that efficient $\mathrm{CO}_{2}$ removal could be achieved with HFOV in these patients.

\section{Materials and methods}

This observational study was done at the medical ICU of the University Medicine of Greifswald between October 2010 and June 2014. The study was approved by the institutional ethics committee at Ernst Moritz Arndt University of Greifswald, who waived the need for informed consent.

Included were all patients with ARDS (novel definition [21], partly adapted retrospectively) of pulmonary origin who received HFOV for respiratory acidosis under lungprotective ventilation with tidal volumes of $6 \mathrm{ml}$ per $\mathrm{kg}$ of ideal body weight. HFOV was begun in the case of $\mathrm{pH}<7.26$. If ARDS was accompanied by a cor pulmonale with hemodynamic instability necessitating catecholamines, the threshold for change to HFOV was a milder hypercapnia ( $\mathrm{pH}<7.30)$. Cor pulmonale was diagnosed by bedside echocardiography (routinely done in every ARDS patient in the initial course) if dilatation of the right ventricle (in apical four-chamber view basal right ventricular diameter $\geq$ left ventricular diameter) and reduced right ventricular contractility were present (tricuspid annular plane systolic excursion $<15 \mathrm{~mm}$ ). ARDSpulm was diagnosed if a primary pulmonary insult was obvious (as in pneumonia or aspiration) or an inhomogeneous pulmonary CT pattern was evident without a pathogenetic role of systemic inflammation. Patients were excluded from the analysis, if the arterial partial pressure of oxygen/ fraction of inspired oxygen $\left(\mathrm{PaO}_{2} / \mathrm{FiO}_{2}\right)$ ratio was lower than $60 \mathrm{mmHg}$, necessitating rescue procedures to improve oxygenation. HFOV was not used if therapy was to be limited because of terminal illness or patient's advance directive, or if HFOV was contraindicated because of severe airway obstruction or intracranial hypertension [20].
Prior to HFOV in all study patients, pressure-controlled conventional ventilation (using a standard ventilator (Evita ${ }^{\text {тा" }}$, Fa Dräger, Lübeck, Germany)) had been optimized in the following way: determination of the positive endexpiratory pressure (PEEP) optimum for oxygenation by a PEEP trial, adjustment of inspiratory pressure to achieve Vts not larger than $6 \mathrm{ml}$ per $\mathrm{kg}$ of ideal body weight, and maximizing respiratory frequency leaving no zero expiratory flow time, but allowing complete expiration. The PEEP trial was performed with a stepwise increase of PEEP level (steps of $2 \mathrm{cmH}_{2} \mathrm{O}$ ) and evaluation of $\mathrm{PaO}_{2}$ and arterial partial pressure of carbon dioxide $\left(\mathrm{PaCO}_{2}\right)$ at every step. According to the approach proposed by Rouby to reduce the risk of overinflation in patients with focal loss of aeration, we started with PEEP 5 to $8 \mathrm{cmH}_{2} \mathrm{O}$ [18]. Patients were sedated according to the local standard operating procedure with propofol and sufentanyl. Muscle relaxants were applied in case of impossibility to achieve patient-ventilator synchrony.

The ICU team has several years' experience with HFOV. The ventilator used was Vision alpha ${ }^{\mathrm{Tm}}$, Novalung $\mathrm{GmbH}$, Heilbronn, Germany. Frequency was initially set to a frequency of $5 \mathrm{~Hz}$. A higher start frequency was chosen if a too rapid $\mathrm{PaCO}_{2}$ decrease was a concern, that is in case of severe acidosis with $\mathrm{pH}<7.15$. The resulting cycle volume is automatically $90 \%$ of the maximal frequency-dependent cycle volume (at $5 \mathrm{~Hz} 315 \mathrm{ml}$ ); it can manually be increased up to $100 \%$. This was done in case of persisting hypercapnia at a frequency of $5 \mathrm{~Hz}$. A cuff leak was not used. Inspiratory to expiratory ratio (I:E) is fixed at 1:1. To optimize lung protection, HFOV frequency was increased in the case of reaching a normal $\mathrm{pH}$ and was adjusted to the greatest value that still resulted in an arterial $\mathrm{pH}<7.29$ [22]. Blood gases were checked after the first 30 and 60 minutes of HFOV, then at least two times per shift. Mean airway pressure (mPaw) was set equal to the actual mPaw of the conventional ventilation. As oxygenation was not critically impaired and there was a lower recruitment potential and a higher risk of volutrauma in inhomogeneous ARDS, we refrained from increasing $\mathrm{mPaw}$ when changing to HFOV. Sedation was continued in the above mentioned manner. A chest X-ray was taken within 24 hours to rule out overinflation [23].

Outcome parameter was the change in $\mathrm{PaCO}_{2}$ after 1 and 24 hours of HFOV, compared to $\mathrm{PaCO}_{2}$ pre-HFOV. Statistical analysis was done using paired $t$ test. Values are given as mean \pm standard deviation. Further data were collected including etiology of respiratory failure, simplified acute physiology score II (SAPS II), duration and setting of pre-HFOV ventilation and of HFOV, 30-day mortality and HFOV-related adverse events. Required minute ventilation (MV) for normal $\mathrm{PaCO}_{2}$ (MV $\mathrm{x}$ $\mathrm{PaCO}_{2} / 40$ ) was calculated additionally as surrogate for dead space [24]. 


\section{Results}

Eighty-three ARDS patients were treated from October 2010 at this ICU. Twenty-six patients received HFOV because of hypercapnia, most with moderate ARDS. Baseline data are recorded in Table 1.

HFOV was begun $17 \pm 22 \mathrm{~h}$ after start of mechanical ventilation. Initially, a frequency of 5 to $6 \mathrm{~Hz}$ was used and an mPaw between 15 and $28 \mathrm{cmH}_{2} \mathrm{O}$ (median $18 \mathrm{cmH}_{2} \mathrm{O}$ ). In one patient, pressure had to be reduced because of radiographic signs of overinflation.

After the first hour of HFOV, $\mathrm{PaCO}_{2}$ was significantly reduced $(-14 \mathrm{mmHg}, P<0.01$; see Table 2). Reduction of $\mathrm{PaCO}_{2}$ was seen in all but two patients in whom $\mathrm{PaCO}_{2}$ did not improve despite increasing cycle volume. They received additional extracorporeal lung support (iLA $^{\text {ma }}$ membrane ventilator, Novalung GmbH, Heilbronn, Germany). These patients were therefore omitted from the 24-hour analysis of $\mathrm{PaCO}_{2}$. In the remaining 24 patients, a

Table 1 Baseline data and concomitant therapy

\begin{tabular}{|c|c|}
\hline Number of patients & 26 \\
\hline Age (years) & $63 \pm 16$ \\
\hline Male sex & $16(61.5 \%)$ \\
\hline SAPS $\|$ & $55 \pm 15$ \\
\hline \multicolumn{2}{|l|}{ ARDS } \\
\hline Severe & $6(23 \%)$ \\
\hline Moderate & $19(73 \%)$ \\
\hline Mild & $1(4 \%)$ \\
\hline \multicolumn{2}{|l|}{ Diagnosis } \\
\hline Pneumonia & $22(85 \%)$ \\
\hline Granulomatosis with polyangiitis & $1(3.8 \%)$ \\
\hline Extrinsic allergic alveolitis & $1(3.8 \%)$ \\
\hline Bronchiolitis obliterans with organizing pneumonia & $1(3.8 \%)$ \\
\hline Unknown origin & $1(3.8 \%)$ \\
\hline \multicolumn{2}{|l|}{ Ventilation prior to HFOV (all BIPAPassist) } \\
\hline Duration (hours) & $17 \pm 22$ \\
\hline PEEP $\left(\mathrm{cmH}_{2} \mathrm{O}\right)$ & $12[6-20]$ \\
\hline Inspiratory pressure $\left(\mathrm{cmH}_{2} \mathrm{O}\right)$ & 27 [18-36] \\
\hline Tidal volume (ml) & $455 \pm 108$ \\
\hline Tidal volume (ml/kg of ideal body weight) & $6.6 \pm 0.9$ \\
\hline Minute ventilation (I/min) & $9.6 \pm 1.8$ \\
\hline Frequency & $22 \pm 6$ \\
\hline $\mathrm{MV} \times \mathrm{PaCO}_{2} / 40(\mathrm{I} / \mathrm{min})$ & $15.6 \pm 3.0$ \\
\hline Proning & $6(23 \%)$ \\
\hline \multicolumn{2}{|c|}{$\begin{array}{l}\text { Values are given as number (percentage), mean } \pm \text { standard deviation, or } \\
\text { median [range], respectively; } \mathrm{MV} \times \mathrm{PaCO} / 40 \text {, required minute ventilation } \\
\text { for normal } \mathrm{PaCO}_{2} \text {. SAPS II, simplified acute physiology score } \mathrm{Il} ; \mathrm{ARDS} \text {, acute } \\
\text { respiratory distress syndrome; } \mathrm{HFOV} \text {, high-frequency oscillation ventilation; } \\
\text { PEEP, positive end-expiratory pressure; } \mathrm{MV} \text {, minute ventilation; } \mathrm{PaCO}_{2} \text {, arterial } \\
\text { partial pressure of } \mathrm{CO}_{2} \text {. }\end{array}$} \\
\hline
\end{tabular}

Table 2 Blood gas analyses before and during

high-frequency oscillation ventilation (HFOV)

\begin{tabular}{lccccc}
\hline & $\begin{array}{l}\text { Before } \\
\text { HFOV }\end{array}$ & $\begin{array}{l}\text { After 1 h } \\
\text { HFOV }\end{array}$ & $\begin{array}{l}\boldsymbol{P} \\
\text { After 24 h }\end{array}$ & $\boldsymbol{P}$ \\
\hline $\begin{array}{l}\text { Number of } \\
\text { patients }\end{array}$ & 26 & 26 & & 24 & \\
$\mathrm{PaCO}_{2}(\mathrm{mmHg})$ & $67.6 \pm 12.3$ & $53.9 \pm 13.7$ & $<0.001$ & $50.4 \pm 17.3$ & $<0.001$ \\
$\mathrm{pH}$ & $7.20 \pm 0.069$ & $7.28 \pm 0.095$ & $<0.001$ & $7.34 \pm 0.052$ & $<0.001$ \\
$\mathrm{PaO}_{2} / \mathrm{F}_{\mathrm{i}} \mathrm{O}_{2}$ & $139 \pm 49$ & $125 \pm 50$ & 0.17 & $155 \pm 52$ & 0.16 \\
$(\mathrm{mmHg})$ & & & & & \\
\hline $\mathrm{m}^{2}$ & & & & & \\
\hline
\end{tabular}

$P$ values of paired $t$ test. Two patients receiving extracorporeal lung support were omitted from 24-hour analysis. Values are given as mean \pm standard deviation. $\mathrm{PaCO}_{2}$, arterial partial pressure of carbon dioxide; $\mathrm{PaO}_{2}$, arterial partial pressure of oxygen; $\mathrm{FiO}_{2}$, fraction of inspired oxygen.

significant decrease of $\mathrm{PaCO}_{2}$ persisted $(-17 \mathrm{mmHg}$ after $24 \mathrm{~h} ; P<0.01)$, see Table 2 . In another patient, the improved $\mathrm{CO}_{2}$ clearance could not be sustained by HFOV, and extracorporeal lung support had to be applied 7 days later.

After 24 hours, HFOV frequency had been adjusted to $6 \mathrm{~Hz}$ (median, range 5 and $10 \mathrm{~Hz}$ ); in six patients no increase of frequency had been possible, in eleven patients frequency after $24 \mathrm{~h}$ was $6 \mathrm{~Hz}$, in seven patients a frequency of greater than 6 could be chosen. mPaw after $24 \mathrm{~h}$ was between 15 and $25 \mathrm{cmH}_{2} \mathrm{O}$ (median $19 \mathrm{cmH}_{2} \mathrm{O}$ ). Oxygenation remained unchanged after 1 and $24 \mathrm{~h}$ (Table 2).

Twenty-two of the 23 patients without extracorporeal lung assist (ECLA) improved and could be switched back to conventional ventilation after $177( \pm 94)$ hours. One patient died on HFOV. Twenty patients $(77 \%$ of the whole cohort) were alive on day 30, 15 (58\%) survived to hospital discharge. Six patients died from extrapulmonary reasons, five from nonresolving lung failure. Complications related to HFOV were not observed throughout the study period. In particular, there were no radiographic or clinical signs of barotrauma in any patient.

\section{Discussion}

In ARDSpulm with hypercapnic failure of conventional ventilation, HFOV - implemented early in the course and refraining from increasing mPaw - could effectively remove $\mathrm{CO}_{2}$. This was observed in $92 \%$ of the patients in this case series. In children, an effective $\mathrm{CO}_{2}$ removal has been demonstrated by HFOV [25]. Several studies in adults, however, found $\mathrm{PaCO}_{2}$ increasing or unchanged during HFOV [12,13,26-28]. Lubnow et al. used an algorithm with initiating HFOV only if $\mathrm{pH}>7.25$ in persistent severe ARDS, and ECLA if $<7.25$ [29]. The two recent meta-analyses again showed no significant difference in ventilation efficiency or $\mathrm{PaCO}_{2}[11,30]$. So in general, HFOV is not seen as a tool for ventilation failure. In fact, the combination with extracorporeal $\mathrm{CO}_{2}$ 
removal is considered repeatedly [28,31,32]. We used HFOV specifically for $\mathrm{CO}_{2}$ removal in patients with ARDSpulm. HFOV has been considered to be a very lung-protective mode. This is expected to be especially relevant for inhomogeneous lung injury in ARDSpulm with consolidation adjacent to normally compliant alveoli, which in this setting may experience cyclic volutrauma with conventional ventilation due to preferential airflow into these segments [3]. HFOV due to its special mode avoids this drawback. Furthermore, in this subset of mainly focal ARDS, there is lower recruitment potential [33] and lower PEEP levels are recommended [18], whereas higher PEEP may propagate an infection or lead to overdistension [34]. Therefore, we decided not to increase the mPaw under conventional ventilation. This is in contrast to the application in recent studies $[6,7,12]$. Oxygenation did not deteriorate despite leaving mPaw unchanged. Barotrauma did not occur in this setting of HFOV, but has been reported in substantial proportions of patients in previous studies $[9,14,22]$.

Compared to most studies, which did not show an improvement in $\mathrm{PaCO}_{2}$, there are some differences: the patients in this study mainly had moderate ARDS; whereas others dealt with severe ARDS $[9,27,35]$. As oxygenation was acceptable under conventional ventilation, we could refrain from the rather high distension pressures that are frequently inevitable in hypoxemic ARDS. Higher airway pressures have been shown to be associated with lower $\mathrm{CO}_{2}$ clearance [9], whereas some data suggest that lower mPaws on HFOV may result in more effective ventilation. In patients with chronic obstructive pulmonary disease (COPD) using mPaw in the same range as we did, a sufficient $\mathrm{CO}_{2}$ removal was achieved [36]. Two further studies are in line with our results: Fessler et al. demonstrated a sufficient $\mathrm{CO}_{2}$ clearance in patients in whom HFOV was initiated partly for ventilation failure [22]. Camparota reported a significant decrease in $\mathrm{PaCO}_{2}$ in severe ARDS, predominantly of extrapulmonary origin, with a greater effect in patients with more severe disease and lower respiratory system compliance. They supposed that extrapulmonary origin implying more recruitment potential - was an important factor for the response to HFOV [10]. In contrast, we found a significant effect in moderate ARDSpulm with more severe pre-HFOV hypercapnia.

Why use HFOV at all after the most recent studies? Two recent studies [6,7] did not show a mortality benefit for HFOV in ARDS, as did two recent meta-analyses $[11,30]$. These results do not preclude a benefit of this ventilation mode in special patients or circumstances [37]. The use in oxygenation failure remains an indication. Furthermore, HFOV was used successfully in combination with extracorporeal membrane oxygenation (ECMO) in posttraumatic ARDS to recruit a lung with minimal compliance [38]. We used HFOV in patients with respiratory acidosis under protective ventilation. We implemented HFOV early in the course when initial optimizations of ventilation resulted in $\mathrm{pH}<7.26$. This $\mathrm{pH}$ threshold for intervention is in accordance to other different studies [29,39] and a consensus article [20].

Initiation of HFOV might not have been the only possibility in the reported patients. Those with $\mathrm{pH} \geq 7.20$ under ventilation with $\mathrm{Vt} 6 \mathrm{ml} / \mathrm{kg}$ could have remained on conventional ventilation. There are, however, concerns regarding adverse effects of hypercapnia $[40,41]$. Furthermore, in focal ARDS even a Vt of $6 \mathrm{ml}$ per $\mathrm{kg}$ may result in hyperinflation $[34,42]$. As Vt was already at the higher margin, we aimed to minimize hypercapnia with an alternative ventilation technique, which is supposed to be more protective [1]. With $\mathrm{pH}<7.20$, conventional ventilation could have been complemented by extracorporeal $\mathrm{CO}_{2}$ elimination, which was regarded as more invasive and therefore reserved as a fallback solution. We actually used ECLA when HFOV failed to improve $\mathrm{CO}_{2}$ clearance. In a similar way, Lubnow et al. treated their patients with ARDS with initial HFOV [29].

There are several limitations of this study: this is a retrospective analysis of a small sample size. With HFOV far away from being a standard procedure, we report our experience in a clearly defined subgroup of patients with ARDS, including all consecutive ones in a definite period. Furthermore, we did not examine parameters of pulmonary stress or inflammation, so we cannot draw conclusions regarding benefit of this alternative strategy.

\section{Conclusions}

In a high percentage of ARDSpulm with hypercapnic failure of lung-protective conventional ventilation, we found effective $\mathrm{CO}_{2}$ removal by $\mathrm{HFOV}$ instituted early in the course and using distending pressures equal to that of the preceding conventional ventilation. These patients may benefit from HFOV as an especially lung-protective strategy. The role of HFOV in hypercapnia management facing different options, including extracorporeal techniques, remains to be determined.

\section{Key messages}

- Protective ventilation in ARDS may lead to severe respiratory acidosis necessitating an alternative or additional approach.

- With HFOV a more effective $\mathrm{CO}_{2}$ elimination may be achievable compared to conventional protective ventilation in ARDSpulm.

- HFOV may be an alternative in hypercapnic failure of protective ventilation in patients with ARDS. 


\section{Abbreviations}

ARDS: acute respiratory distress syndrome; ARDSpulm: ARDS of pulmonary origin; COPD: chronic obstructive pulmonary disease; CT: computed tomography; ECLA: extracorporeal lung assist; ECMO: extracorporeal membrane oxygenation; $\mathrm{FiO}_{2}$ : fraction of inspired oxygen; HFOV: highfrequency oscillation ventilation; I:E: inspiratory to expiratory ratio; mPaw: mean airway pressure; $\mathrm{MV}$ : minute ventilation; $\mathrm{PaCO}_{2}$ : arterial partial pressure of carbon dioxide; $\mathrm{PaO}_{2}$ : arterial partial pressure of oxygen; PEEP: positive end-expiratory pressure; SAPS II: simplified acute physiology score Il; Vt: tidal volume.

\section{Competing interests}

The authors declare that they have no competing interests.

\section{Authors' contributions}

SF designed the study and participated in data acquisition, analysis and interpretation as well as drafting of the manuscript. PA and SSS participated in data analysis and interpretation, and drafting of the manuscript. All three authors have approved the submitted version of the manuscript.

Received: 21 January 2015 Accepted: 20 April 2015

Published online: 01 May 2015

\section{References}

1. Imai Y, Slutsky AS. High-frequency oscillatory ventilation and ventilator-induced lung injury. Crit Care Med. 2005;33:S129-34.

2. Ip T, Mehta S. The role of high-frequency oscillatory ventilation in the treatment of acute respiratory failure in adults. Curr Opin Crit Care. 2012;18:70-9.

3. Stawicki SP, Goyal M, Sarani B. High-frequency oscillatory ventilation (HFOV) and airway pressure release ventilation (APRV): a practical guide. J Intensive Care Med. 2009;24:215-29.

4. Pillow JJ. High-frequency oscillatory ventilation: mechanisms of gas exchange and lung mechanics. Crit Care Med. 2005;33:S135-41.

5. Slutsky AS, Drazen FM, Ingram Jr RH, Kamm RD, Shapiro AH, Fredberg Ju, et al. Effective pulmonary ventilation with small-volume oscillations at high frequency. Science. 1980;209:609-71.

6. Ferguson ND, Cook DJ, Guyatt GH, Mehta S, Hand L, Austin P, et al. High-frequency oscillation in early acute respiratory distress syndrome. N Engl J Med. 2013;368:795-805.

7. Young D, Lamb SE, Shah S, MacKenzie I, Tunnicliffe W, Lall R, et al. High-frequency oscillation for acute respiratory distress syndrome. N Engl J Med. 2013;368:806-13

8. Chan KP, Stewart TE. Clinical use of high-frequency oscillatory ventilation in adult patients with acute respiratory distress syndrome. Crit Care Med. 2005;33:S170-4.

9. Adhikari NK, Bashir A, Lamontagne F, Mehta S, Ferguson ND, Zhou Q, et al. High-frequency oscillation in adults: a utilization review. Crit Care Med. 2011;39:2631-44

10. Camporota L, Sherry T, Smith J, Lei K, McLuckie A, Beale R. Physiological predictors of survival during high-frequency oscillatory ventilation in adults with acute respiratory distress syndrome. Crit Care. 2013;17:R40.

11. Huang CT, Lin HH, Ruan SY, Lee MS, Tsai YJ, Yu CJ. Efficacy and adverse events of high-frequency oscillatory ventilation in adult patients with acute respiratory distress syndrome: a meta-analysis. Crit Care. 2014;18:R102.

12. Derdak S, Mehta S, Stewart TE, Smith T, Rogers M, Buchman TG, et al. High-frequency oscillatory ventilation for acute respiratory distress syndrome in adults: a randomized, controlled trial. Am J Respir Crit Care Med. 2002;166:801-8.

13. Sud S, Sud M, Friedrich JO, Meade MO, Ferguson ND, Wunsch $H$, et al. High frequency oscillation in patients with acute lung injury and acute respiratory distress syndrome (ARDS): systematic review and meta-analysis. BMJ. 2010;340:c2327.

14. Mehta S, Granton J, MacDonald RJ, Bowman D, Matte-Martyn A, Bachman T, et al. High-frequency oscillatory ventilation in adults: the Toronto experience. Chest. 2004;126:518-27.

15. Pelosi $P$, Gattinoni L. Acute respiratory distress syndrome of pulmonary and extra-pulmonary origin: fancy or reality? Intensive Care Med. 2001:27:457-60.

16. Gattinoni L, Caironi P, Pelosi P, Goodman LR. What has computed tomography taught us about the acute respiratory distress syndrome? Am J Respir Crit Care Med. 2001;164:1701-11.
17. Gattinoni L, Carlesso E, Caironi P. Stress and strain within the lung Curr Opin Crit Care. 2012;18:42-7.

18. Rouby JJ, Lu Q, Goldstein I. Selecting the right level of positive end-expiratory pressure in patients with acute respiratory distress syndrome. Am J Respir Crit Care Med. 2002;165:1182-6.

19. Pillow JJ. Tidal volume, recruitment and compliance in HFOV: same principles, different frequency. Eur Respir J. 2012;40:291-3.

20. Fessler HE, Derdak S, Ferguson ND, Hager DN, Kacmarek RM, Thompson BT, et al. A protocol for high-frequency oscillatory ventilation in adults: results from a roundtable discussion. Crit Care Med. 2007;35:1649-54.

21. Force ADT, Ranieri VM, Rubenfeld GD, Thompson BT, Ferguson ND, Caldwell $E$, et al. Acute respiratory distress syndrome: the Berlin Definition. JAMA. 2012;307:2526-33.

22. Fessler HE, Hager DN, Brower RG. Feasibility of very high-frequency ventilation in adults with acute respiratory distress syndrome. Crit Care Med. 2008:36:1043-8.

23. Bollen CW, van Well GT, Sherry T, Beale RJ, Shah S, Findlay G, et al. High frequency oscillatory ventilation compared with conventional mechanical ventilation in adult respiratory distress syndrome: a randomized controlled trial [ISRCTN24242669]. Crit Care. 2005;9:R430-9.

24. Wexler HR, Lok P. A simple formula for adjusting arterial carbon dioxide tension. Can Anaesth Soc J. 1981;28:370-2.

25. Slee-Wijffels FY, van der Vaart KR, Twisk JW, Markhorst DG, Plotz FB. High-frequency oscillatory ventilation in children: a single-center experience of 53 cases. Crit Care. 2005:9:R274-9.

26. Andersen FA, Guttormsen AB, Flaatten HK. High frequency oscillatory ventilation in adult patients with acute respiratory distress syndrome-a retrospective study. Acta Anaesthesiol Scand. 2002;46:1082-8.

27. Finkielman JD, Gajic O, Farmer JC, Afessa B, Hubmayr RD. The initial Mayo Clinic experience using high-frequency oscillatory ventilation for adult patients: a retrospective study. BMC Emerg Med. 2006;6:2.

28. Kredel M, Brederlau J, Wunder C, Wurmb TE, Kranke P, Roewer N, et al. High-frequency oscillatory ventilation with and without arteriovenous extracorporeal lung assist in patients with severe respiratory failure. J Crit Care. 2012;27:182-91.

29. Lubnow M, Luchner A, Philipp A, Buchner S, Jeron A, Karagiannidis C, et al. Combination of high frequency oscillatory ventilation and interventional lung assist in severe acute respiratory distress syndrome. J Crit Care. 2010;25:436-44.

30. Gu XL, Wu GN, Yao YW, Shi DH, Song Y. Is high-frequency oscillatory ventilation more effective and safer than conventional protective ventilation in adult acute respiratory distress syndrome patients? A meta-analysis of randomized controlled trials. Crit Care. 2014;18:R111.

31. Taki K, Huang DT. High-frequency oscillation in early adult respiratory distress syndrome. Crit Care. 2014;18:310.

32. Brederlau J, Muellenbach R, Kredel M, Kuestermann J, Anetseder M, Greim C, et al. Combination of arteriovenous extracorporeal lung assist and high-frequency oscillatory ventilation in a porcine model of lavage-induced acute lung injury: a randomized controlled trial. J Trauma. 2007;62:336-46. discussion 345-336.

33. Muellenbach RM, Wunder C, Brederlau J. High-frequency ventilation is/is not the optimal physiological approach to ventilate ARDS patients. J Appl Physiol. 2008;104:1236-39.

34. Grasso S, Stripoli T, De Michele M, Bruno F, Moschetta M, Angelelli G, et al. ARDSnet ventilatory protocol and alveolar hyperinflation: role of positive end-expiratory pressure. Am J Respir Crit Care Med. 2007;176:761-7.

35. Charles PE, Martin L, Etienne M, Croisier D, Piroth L, Lequeu C, et al. Influence of positive end-expiratory pressure (PEEP) on histopathological and bacteriological aspects of pneumonia during low tidal volume mechanical ventilation. Intensive Care Med. 2004;30:2263-70.

36. Frerichs I, Achtzehn U, Pechmann A, Pulletz S, Schmidt EW, Quintel M, et al. High-frequency oscillatory ventilation in patients with acute exacerbation of chronic obstructive pulmonary disease. J Crit Care. 2012;27:172-81.

37. Goffi A, Ferguson ND. High-frequency oscillatory ventilation for early acute respiratory distress syndrome in adults. Curr Opin Crit Care. 2014;20:77-85.

38. Gothner M, Buchwald D, Schlebes A, Strauch JT, Schildhauer TA, Swol J. Use of extracorporeal membrane oxygenation in combination with high-frequency oscillatory ventilation in post-traumatic ARDS. Acta Anaesthesiol Scand. 2013;57:391-4.

39. Terragni PP, Del Sorbo L, Mascia L, Urbino R, Martin EL, Birocco A, et al. Tidal volume lower than $6 \mathrm{ml} / \mathrm{kg}$ enhances lung protection: role of extracorporeal carbon dioxide removal. Anesthesiology. 2009;111:826-35. 
40. O'Croinin D, Ni Chonghaile M, Higgins B, Laffey JG. Bench-to-bedside review: Permissive hypercapnia. Crit Care. 2005;9:51-9.

41. Swenson ER. Therapeutic hypercapnic acidosis: pushing the envelope. Am J Respir Crit Care Med. 2004;169:8-9.

42. Terragni PP, Rosboch G, Tealdi A, Corno E, Menaldo E, Davini O, et al. Tidal hyperinflation during low tidal volume ventilation in acute respiratory distress syndrome. Am J Respir Crit Care Med. 2007;175:160-6.

Submit your next manuscript to BioMed Central and take full advantage of:

- Convenient online submission

- Thorough peer review

- No space constraints or color figure charges

- Immediate publication on acceptance

- Inclusion in PubMed, CAS, Scopus and Google Scholar

- Research which is freely available for redistribution 